Научная статья

УДК 595.785. 591.5

DOI: $10.18101 / 2542-0623-2021-1-7-13$

\title{
RHODOSTROPHIA JACULARIA (HUBNER, 1813) (LEPIDOPTERA: GEOMETRIDAE) В ЗАБАЙКАЛЬЕ
}

\section{Т. В. Гордеева, С. Ю. Гордеев}

(C) Гордеева Татьяна Валерьевна

кандидат биологических наук,

Институт общей и экспериментальной биологии СО РАН

Россия, 670047, г. Улан-Удэ, ул. Сахьяновой, 6

tagor71@mail.ru

\section{(C) Гордеев Сергей Юрьевич}

кандидат биологических наук, Институт общей и экспериментальной биологии СО РАН Россия, 670047, г. Улан-Удэ, ул. Сахьяновой, 6 gordeevs07@mail.ru

Аннотация. Rhodostrophia jacularia Hb. - евросибирский степной вид из группы пядениц-стеррин. Его ареал охватывает Центральную Европу и Азию, на юго-востоке достигает районов Внутренней Монголии. В Забайкалье он встречается в зональных степях Селенгинской и Ононской Даурии, в местах произрастания гониолимона красивого (Goniolimon speciosum (L.) Boiss. — кормового растения его гусеницы. Жизненный цикл Rh. jacularia характеризуется зимовкой яйца, развитием гусеницы в весеннее время, окукливанием в конце мая, вылетом имаго в начале лета, спариванием и откладкой яиц в конце июня - начале июля.

Ключевые слова: Селенгинское среднегорье, Даурия, Маньчжурия, суббореальный вид, пяденицы-стеррины, Goniolimon.

Благодарности. Авторы благодарят О. В. Корсуна (г. Чита, ЗабГУ) - за любезно предоставленный им материал из Внутренней Монголии; С. Г. Рудых (Улан-Удэ, ИОЭБ СО РАН) - за экземпляры бабочек из Иркутской области. Работа выполнена в рамках проекта СО РАН № VI.51.1.2. «Реакции животного мира Байкальского региона на глобальные изменения климата» (Регистрационный номер: АААА-А17117011810035-6; ФАНО 0337-2016-0002).

\section{Для цитирования}

Гордеева Т. В., Гордеев С. Ю. Rhodostrophia jacularia (Hübner, 1813) (Lepidoptera: Geometridae) в Забайкалье // Природа Внутренней Азии. Nature of Inner Asia. 2021. № 1(17). C. 7-23. DOI: 10.18101/2542-0623-2021-1-7-13

\section{Введение}

Виды пядениц-стеррин из рода Rhodostrophia в своём распространении ограничены пределами суббореального пояса. Ареал Rh. jacularia Hb. охватывает центральную часть Евразии и простирается от причерноморских степей России, 
Южной Украины и Турции, далее на восток - через Северный Казахстан в Северо-Западный Китай и Монголию, и по горам Южной Сибири - до Даурии. В Прибайкальских и Забайкальских степях этот вид обычен, но малоизучен, а его гусеница до недавнего времени была неизвестна.

\section{Район исследований и методика сбора материала}

Основная часть материала собрана в пределах Селенгинского среднегорья (Республика Бурятия), два экземпляра - близ западного побережья оз. Байкал (Иркутская область), один экземпляр - на северо-востоке Внутренней Монголии (Китай) (карта). Бабочки отловлены днем с помощью сачка и ночью - на свет ультрафиолетовой лампы. Гусеницы собраны при осмотре Goniolimon speciosum (L.) Boiss. Личинок выращивали в садках до окукливания. Куколок содержали отдельно, до вылета имаго. Всего изучено около 30 экземпляров бабочек и гусениц. Материал хранится в коллекции лаборатории экологии и систематики животных ИОЭБ СО РАН (Улан-Удэ).

\section{Пункты сбора материала}

Ацула - местность в устье реки Темник в 35-50 км ЮЗ г. Гусиноозёрск. Караганниково-злаковая степь.

Бегул - залив в районе западного побережья озера Байкал в устье реки Анга. Мелкодерновинно-злаковые типчаковые степи.

Далайнор (Хулун-Нур) - озеро в северо-восточной части Внутренней Монголии (Китай). Ковыльные степи и солончаковые луга.

Модотый (гора Солога, Соложка с максимальной высотой 670 м над ур. м.) - предгорье ЮВ склона хребта Улан-Бургасы, дерновинно-злаковые степи в 3-5 км СВ поселка Онохой.

Онохой - крупный населенный пункт в нижнем течении реки Уды в 40 км В г. Улан-Удэ. Котловинные степи, сухие террасы с сосняками.

Уточи - кордон у протоки, соединяющей озера Зун-Торей и Барун-Торей. Ковыльные степи и солончаковые луга.

Хара-Шибирь - предгорья хребта Улан-Бургасы в 30 км СВ поселка Онохой. Сухостепные, с сосной, склоны южной экспозиции.

Шаманские горы - рельефные крутые склоны на сглаженных сопках с вершиной гора Даши-Бадар (854 м над ур. м.) по правобережью в нижнем течении Селенги вблизи поселка Тапхар (Топхар) в 25-30 км 3 г. Улан-Удэ. Каменисто-злаковые, пологосклоновые карагановые и мелкозлаковые степи с сосной и ильмовником.

\section{Rhodostrophia jacularia (Hübner, 1813)}

Черноруд [Васильева, 1989]; Муртой, Гусиное озеро [Sihvonen, Nupponen, 2005]; Онхолой [Берлов, Берлов, 2006]; Рытый, Малое море [Махов, 2017]; Ацула, Онохой [Гордеева, Гордеев, 2007]; Заповедник «Даурский», Цасучейский бор [Костюк и др., 1994]; Уточи [Корсун, 2017].

\section{Материал}

Иркутская область: Бегул, 29.06.1993: 2 самца (ручной сбор, С. Г. Рудых).

Бурятия: Модотый, 5.06.2007: 1 самец; 11.05.2010: 5 гусениц; 18.05.2011:

1 гусеница (ручной сбор, С. Ю. Гордеев); Хара-Шибирь, 9.05.2008: около 
T. В. Гордеева, С. Ю. Гордеев. Rhodostrophia jacularia (Hübner, 1813)

(Lepidoptera: Geometridae) в Забайкалье

десятка гусениц (ручной сбор, Т. В. Гордеева); Шаманские горы, 10-12.05.2008: 1 гусеница, 1 самка вывелась 12.06.2008 (ручной сбор, Т. В. Гордеева); 10.06.2008: 1 самка (на свет, Гордеев С. Ю.).

Китай: Далайнор, 7.08.2007: 1 самец (сухие насекомые из плафона лампы, О. В. Корсун).

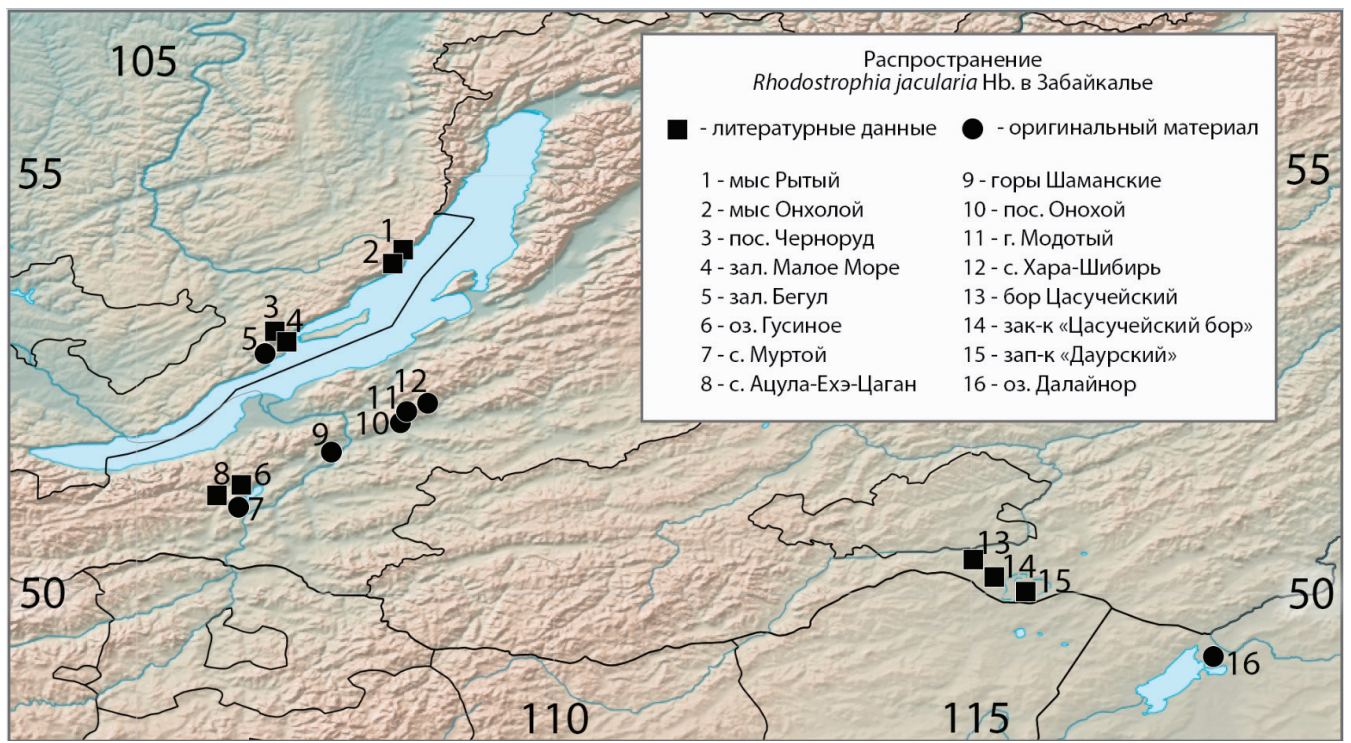

Puc. 1. Пункты сбора материала Rhodostrophia jacularia Hb. и литературные данные о находках

\section{Жизненный цикл}

В Забайкалье Rh. jacularia - моновольтинный вид, зимующий на стадии яйца. С установлением положительных среднесуточных температур в середине апреля зимовка завершается выведением гусеницы с последующим ее питанием на листьях гониолимона красивого (Goniolimon speciosum (L.) Boiss.) (рис. 2.1).

Личинок младших возрастов найти практически невозможно из-за их мелких размеров (менее 1 см) и несквозных погрызов, сделанных ими с нижней стороны плотно прилегающего к земле листа. Гусениц среднего возраста можно обнаружить в конце первой декады мая на кормовом растении по характерным округлым погрызам по краям листа (рис. 2.2). В старших возрастах гусеница достигает трех сантиметров в длину и становится вполне заметна внешне и по следам жизнедеятельности - по характерным краевым повреждениям и округлой сквозной перфорации листьев гониолимона (рис. 2.3).

Строение гусеницы типично для пядениц, характеризующихся отсутствием большей части брюшных ног, при наличии трёх пар настоящих грудных ног, одной пары и концевого подталкивателя на последних брюшных сегментах (рис. 2.4). Как у большинства представителей группы стеррин, тело гусеницы Rh. jacularia уплощено в дорзовентральном направлении с образованием двух выпуклых жестких валиков по бокам вдоль стигмальной линии. 


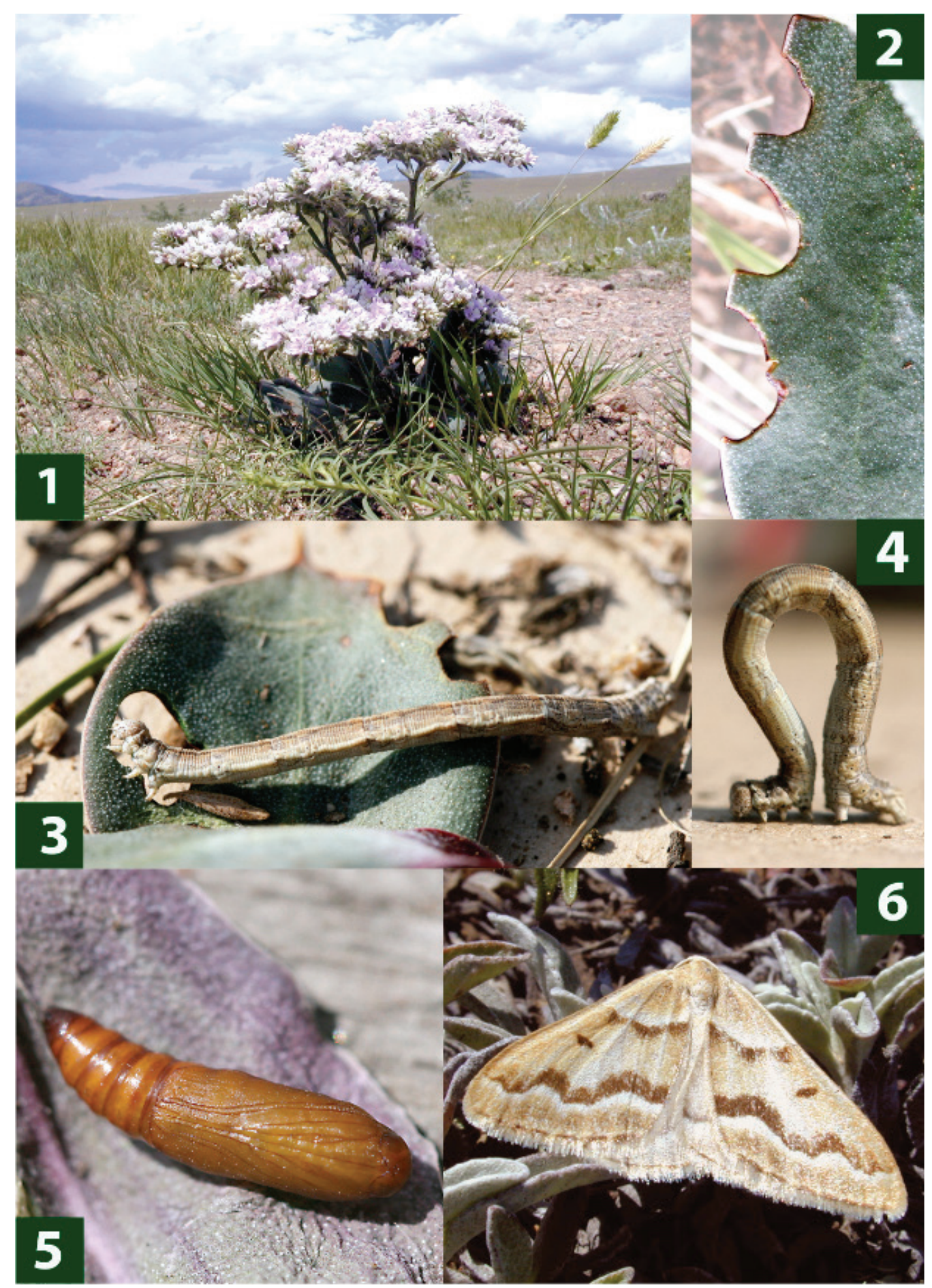

Puc. 2. Жизненный цикл Rhodostrophia jacularia Hb.: 1 - кормовое растение; 2 - лист гониолимона со следами погрызов гусеницами Rh. jacularia Hb.; 3 - питание гусеницы; 4 - гусеница старшего возраста; 5 - куколка; 6 - имаго 
T. В. Гордеева, С. Ю. Гордеев. Rhodostrophia jacularia (Hübner, 1813)

(Lepidoptera: Geometridae) в Забайкалье

Примечания к рис. 2.

note - заметки по работе о совках открытых ландшафтов Южного Забайкалья [Кантер, 1975];

note 1 - из рода Autographa также отмечены виды A. jota L., A. v-aureum Hbn. [=pulchrina (Haworth, 1809)]. Экземпляры этих видов в коллекциях ЛЭиСЖ не найдены;

note 2 - с пригорода Улан-Удэ этот вид приводится как Lithophane ingrica H.S. В коллекциях он не найден, нами в Забайкалье не отмечен в отличие от обычного Lithophane socia $\mathrm{Hfn}$.

note 3 - приводится как Tholera leucohpaea View.;

note 4 - из видов рода Lacanobia (Mamestra) для пригорода Улан-Удэ также отмечаются M. [?] furca Ev., M. w-latinum Hufn. Этих видов в коллекциях ЛЭиСЖ нет;

note 5 - указан как A. inexpectata Alphéraky;

note 6 - как нередкий из окрестностей Улан-Удэ отмечен Agrotis ipsilon Hufn, кроме того, в районе Эрхирика — один экземпляр A. crassa Hbn. [=A. bigramma (Esper, [1790])]. В сборах ЛЭиСЖ они отсутствуют;

note 7 - для окрестностей Улан-Удэ (Эрхирик) отмечен вид Anomogina speciosa Hbn. Вполне возможно, бабочки (5 экз.) были собраны несколько севернее, в верхней части хребта Улан-Бургасы.

Окраска личинки покровительственная, что вкупе со склонностью к каталепсии (в спирально свернутом положении) позволяет ей «слиться» с субстратом в виде сухого листа осоки. В последней декаде мая гусеница приступает к окукливанию, размещаясь под листьями гониолимона в верхних слоях почвы внутри слабооплетенной колыбельки, где проводит 8-10 дней.

Покровы куколки красновато-охристые, кутикула тонкая, прозрачная, слегка пунктированная (рис. 2.5). По нашим наблюдениям, вылет имаго в Забайкалье начинается в конце мая - начале июня и продолжается в течение месяца, завершаясь спариванием и откладкой яиц в конце июня - первой декаде июля. В Ононской Даурии и Внутренней Монголии бабочек отмечали и в августе [Костюк и др., 1994; Sihvonen, Nupponen, 2005], что может свидетельствовать либо о наличии второй генерации, либо о растянутости или смещении периода лета.

Днем вспугнутые бабочки Rh. jacularia быстро и низко перелетают на небольшие расстояния, держась вблизи кормового растения. Они хорошо отличимы по контрастной окраске светло-охристых крыльев с двумя красновато-бурыми медиальными линиями (дважды выгнутыми и неравномерно растушеванными) и ярким дискальным пятном в чуть более тёмном медиальном поле (рис. 2.6).

Ночью имаго могут прилетать на свет лампы. В сравнении с относительно крупными забайкальскими экземплярами самец Rh. jacularia из окрестностей оз. Далайнор более миниатюрный и узкокрылый, что может быть связано с его обитанием в более аридных и открытых ветрам ландшафтах. Случаи узкокрылости, связываемые с адаптацией к суровым условиям окружающей среды, описаны для алтайских самок Rh. jacularia [Sihvonen, Nupponen, 2005].

Материал из Внутренней Монголии позволяет дополнить юго-восточную границу ареала этого вида, включающую предгорья Иньшань (Ejina Banner), Алашань (Alха League) [Ma et al., 1991] и Oрдос (Ordos) [Sihvonen, Nupponen, 2005], до Маньчжурии (Heilongjiang). Rh. jacularia как представитель хортофильной 
группы пядениц, трофически связанных с растениями специфичного биохимического состава [Гордеева, 2009], специализируется на гониолимоне, богатом минералами, органическими кислотами и значительными запасами влаги, что особенно актуально для обитателей иссушенных и обезвоженных ландшафтов.

\section{Литература}

1. Берлов О. Э., Берлов Э. Я. Материалы к фауне и экологии пядениц (Lepidoptera, Geometridae) Прибайкалья // Труды государственного заповедника «Байкало-Ленский». Иркутск, 2006. Вып. 4. С. 102-110. Текст : непосредственный.

2. Васильева Т. Г. К фауне пядениц (Lepidoptera, Geometridae) Южного Прибайкалья // Насекомые и паукообразные Сибири. Иркутск: Изд-во ИГУ, 1989. С. 104-115. Текст : непосредственный.

3. Гордеева Т. В. Фауна и биономия высших разноусых чешуекрылых (Lepidoptera, Metaheterocera) Бурятии: диссертация на соискание ученой степени кандидата биологических наук: 03.02.05 / Гордеева Татьяна Валерьевна [Место защиты: ИСиЭЖ СО РАН]. Новосибирск, 2009. 270 с. Текст : непосредственный.

4. Гордеева Т. В., Гордеев С. Ю. Семейство Geometridae - пяденицы // Чешуекрылые Бурятии. Новосибирск: Издательство СО РАН, 2007. С. 95-148. Текст : непосредственный.

5. Махов И. А. Фауна и экология пядениц (Lepidoptera: Geometridae) Южного Прибайкалья: выпускная квалификационная работа магистра. Санкт-Петербург, 2017. 223 с. Текст : непосредственный.

6. Корсун О. В. Насекомые Даурского заповедника. Полевой атлас // Атласы и путеводители Даурского заповедника. Новосибирск : Дом мира, 2017. 540 с. : ил. Текст : непосредственный.

7. Костюк И. Ю., Будашкин И. Ю., Головушкин М. И. Чешуекрылые заповедника «Даурский». Киев, 1994. 36 с. Текст : непосредственный.

8. Ma Yao, Li Hong-Chang \& Kang Le. The Grassland Insects of Inner Mongolia // Tianze Eldonejo, 1991. 186-191.

9. Sihvonen, Pasi \& Nupponen, Kari. Taxonomy of Rhodostrophia jacularia (Hübner, 1813) - A Sterrhinae moth with variable female wing shape (Lepidoptera: Geometridae). Nota Lepidopterologica. 28. 2005. 113-122.

Статья поступила в редакиию 24.12.2020; одобрена после рецензирования 18.01.2021; принята к публикации 30.03.2021.

\section{RHODOSTROPHIA JACULARIA (HÜBNER, 1813) (LEPIDOPTERA: GEOMETRIDAE) IN TRANSBAIKALIA}

T. V. Gordeeva, S. Yu. Gordeev

Tatyana V. Gordeeva

Cand. Sci. (Biol.)

Institute for General and Experimental Biology SB RAS,

6 Sakhyanovoy St., Ulan-Ude 670047 Russia

tagor71@mail.ru

Sergey Yu. Gordeev

Cand. Sci. (Biol.)

Institute for General and Experimental Biology SB RAS, 
6 Sakhyanovoy St., Ulan-Ude 670047 Russia

gordeevs07@mail.ru

Abstract. Rhodostrophia jacularia $\mathrm{Hb}$. is a Euro-Siberian steppe species from Sterrhinae subfamily. The areal of Rh. jacularia covers Central Europe and Asia and extends to Inner Mongolia (China). In Transbaikalia this species inhabits the steppes of Selenga and Onon Dauria and can be found in places where Goniolimon speciosum (L.) Boiss. grows. It is forage plant for Rh. jacularia caterpillars. Life cycle of Rh. jacularia is characterized by egg overwintering, caterpillar development in spring, pupation in late May, adult emergence in early summer, mating and oviposition in late June - early July.

Keywords: Selenga Highlands, Dauria, Manchuria, subboreal species, Sterrhinae, Goniolimon.

Acknowledgments. The authors are grateful to O. V. Korsun (Chita, Transbaikal State University) for the material provided from Inner Mongolia; S. G. Rudykh (Ulan-Ude, Institute for General and Experimental Biology SB RAS) for specimens of butterflies from Irkutsk Oblast. The work was carried out within the framework of the SB RAS project No. VI.51.1.2. «Response of the Fauna of Baikal Region to Global Climate Changes» (Registration number: AAAA-A17-117011810035-6; FANO 0337-2016-0002).

For citation

Gordeeva T. V., Gordeev S. Yu. Rhodostrophia jacularia (Hübner, 1813) (Lepidoptera: Geometridae) in Transbaikalia. Nature of Inner Asia. 2021; 1(17): 7-13 (In Russ.). DOI: $10.18101 / 2542-0623-2021-1-7-13$

The article was submitted 24.12.2020; approved after reviewing 18.01.2021; accepted for publication 30.03.2021. 